\title{
The impact of shift work induced chronic circadian disruption on IL- 6 and TNF- $\alpha$ immune responses
}

\author{
Anke van Mark ${ }^{1 *}$, Stephan W Weiler ${ }^{2}$, Marcel Schröder ${ }^{1}$, Andreas Otto ${ }^{1}$, Kamila Jauch-Chara ${ }^{3}$, David A Groneberg ${ }^{4}$, \\ Michael Spallek ${ }^{5}$, Richard Kessel ${ }^{1}$, Barbara Kalsdorf ${ }^{6}$
}

\begin{abstract}
AIM: Sleep disturbances induce proinflammatory immune responses, which might increase cardiovascular disease risk. So far the effects of acute sleep deprivation and chronic sleep illnesses on the immune system have been investigated. The particular impact of shift work induced chronic circadian disruption on specific immune responses has not been addressed so far.

Methods: Pittsburgh-Sleep-Quality-Index (PSQI) questionnaire and blood sampling was performed by 225 shift workers and 137 daytime workers. As possible markers the proinflammatory cytokines IL-6 and TNF- $\alpha$ and lymphocyte cell count were investigated. A medical examination was performed and biometrical data including age, gender, height, weight, waist and hip circumference and smoking habits were collected by a structured interview.
\end{abstract}

Results: Shift workers had a significantly higher mean PSQI score than day workers (6.73 vs. 4.66; $p<0.001$ ). Day workers and shift workers had similar serum levels of IL-6 (2.30 vs. 2.67 resp.; $p=0.276)$, TNF- $\alpha$ (5.58 vs. 5.68, resp.; $p=0.841)$ or lymphocytes count (33.68 vs. 32.99 , resp.; $p=0.404$ ). Furthermore there were no differences in cytokine levels (IL-6 $p=0.761$; TNF- $\alpha p=0.759)$ or lymphocyte count $(p=0.593)$ comparing the sleep quality within the cohorts. When this calculation of sleep quality was stratified by shift and day workers irrespective of their sleep quality day workers and shift workers had similar serum levels of IL-6, TNF- $\alpha$ or lymphocytes count. Multiple linear regression analysis showed a significant correlation of lymphocytes count and smoking habits.

Conclusion: Shift work induces chronic sleep debt. Our data reveals that chronic sleep debt might not always lead to an activation of the immune system, as we did not observe differences in lymphocyte count or level of IL-6 or TNF- $\alpha$ serum concentration between shift workers and day workers. Therefore chronic sleep restriction might be eased by a long-term compensating immune regulation which (in healthy) protects against an overstimulation of proinflammatory immune mechanisms and moderates metabolic changes, as they are known from short-term sleep deprivation or sleep related breathing disorders.

\section{Introduction}

Shift-workers are forced to work and sleep against normal chronobiological rhythms: they sleep at times their organism is set to activity and they work when physical and psychical effectiveness is generally low. These contradictious demands induce various indispositions; most frequently sleep disturbances which can cause

\footnotetext{
* Correspondence: anke.van.mark@arbeitsmedizin.uni-luebeck.de
'Institute of Occupational Medicine, University of Lübeck, 23538 Lübeck,

* Correspondence: anke.van.mark@arbeitsmedizin.uni-luebeck.de
${ }^{1}$ Institute of Occupational Medicine, University of Lübeck, 23538 Lübeck, Ratzeburger Allee 160, Germany
}

severe sleep debt [1-6]. Recent research focuses on investigations how these sleep disturbances influence the immune system and if such an activation of the immune system might be linked with cardiovascular disease risks.

Activation of inflammatory immune responses is marked by an increase of proinflammatory cytokines, e.g. Interleukin-1beta (IL-1ß), IL-6 or Tumor-NecrosisFactor alpha (TNF- $\alpha)$. Several authors report an augmentation of these cytokines after acute sleep 
deprivation and thereby an induction of proinflammatory immune responses [7-9]. Cytokine levels correlate with fatique and daytime somnolence [10-12]. Therefore Vgontzas et al. call IL- 6 and TNF- $\alpha$ fatique inducing cytokines [12]. Similar to acute sleep disorders people with a chronic sleep debt due to their obstructive sleep apnoe syndrome show elevated cytokine activity [13-16]. Cytokines regulate cell proliferation and differentiation. Thereby proinflammatory cytokine activation induces the recruitment of lymphocytes and neutrophils. Liu et al. demonstrated an increase of lymphocyte and neutrophil cells after acute sleep deprivation [17].

As inflammatory processes are recognized to play a major role in the pathogenesis of atherosclerosis, serum biomarkers are investigated to estimate emerging cardiovascular risk. There is increasing evidence that proinflammatory conditions and sleep disturbances elevate the risk of cerebrovascular and cardiovascular diseases [13,18-25]. This model may explain the higher cardiovascular diseases risk in shift workers [2,26-28].

So far this knowledge of associations between sleep debt and immune responses has not been related to the socioeconomically important factor shift work. We hypothesize that shift work induced chronic circadian disruption does affect proinflammatory immune responses. As possible markers of these changes in the immune system we investigated the proinflammatory cytokines IL- 6 and TNF- $\alpha$ and measured the lymphocyte cell count.

\section{Materials and methods}

The study was approved by the Research Ethics Committee of the University Schleswig-Holstein Campus Lübeck, Germany (Ref. Az 05-028). Following informed consent, peripheral venous blood was drawn and the Pittsburgh-Sleep-Quality-Index (PSQI) questionnaire was completed by 225 shift workers and 137 daytime workers. A medical examination was performed and biometrical data including age, gender, height, weight, waist and hip circumference and smoking habits were collected by a structured interview. Both cohorts had a similar social background and worked in the industrial sector. Most shift workers worked in a three shift system including night shifts (91\%), 9\% worked in other schedules like permanent night shift, 24-hours or similarly irregular shift schedules.

The mean age of shift workers was 36.4 yrs (SD 9.34) and the mean age of daytime workers 40.1 yrs (SD 7.77; $\mathrm{p}<0.001) .86 .9 \%$ of the shift workers and $75.7 \%$ of the day workers were male $(p=0.010)$. Shift workers and day workers did not differ in their Body Mass Index $\left(\right.$ BMI; $\mathrm{kg} / \mathrm{m}^{2}$ ), (mean 26.62 versus 26.27 respectively, $\mathrm{p}=0.455)$. Shift workers were significantly more smokers than daytime workers ( $41.8 \%$ vs. $27.0 \% ; \mathrm{p}=0.005)$.
The PSQI is a validated instrument composed of 19 self-rated questions for the measurement of sleep quality during the previous month. Higher PSQI-Sum-Scores indicate inferior sleep quality. The questionnaire divides into "good sleeper" (PSQI $\leq 6)$, "poor sleeper" (PSQI 6 $10)$ and "people with chronic sleep disorders" (PSQI $\geq$ 11 ), but the test does not enable to distinguish between different causes of sleep disorders. For this study a total value of 6 was defined the limit for the diagnosis "disturbed sleep", meaning values $\geq 6$ are a proved sign for relevant sleep disturbances, values $<6$ signify none or slight, clinically not relevant sleep disturbances.

Fasting blood samples were withdrawn between 6 to 8 am, promptly centrifugated and aliquots stored at $-40^{\circ} \mathrm{C}$ until analysis. Concentration of IL- 6 and TNF- $\alpha$ were measured by ELISA-techniques as recommended by the manufacturer (Immulite, Los Angeles, Germany). Blood cell count was detected immediately after sampling with an automated hematology analyzer.

Statistical test were performed with descriptive methods, Levene's test for equality of variances, and t-tests for mean comparisons if applicable. Independent dichotomous variables were analyzed by Chi-Square-test, metric data by $\mathrm{t}$-test, correlation coefficients were calculated on a ranked basis by spearman-rho procedure. Significance level was defined as $\mathrm{p}<0.05$. Data were normally distributed. Missing data rate was below $6 \%$.

\section{Results}

Shift workers had a significantly higher mean PSQI score than day workers (6.73 vs. $4.66 ; \mathrm{p}<0.001)$ and significantly more shift workers had pathologically elevated scores $(61.2 \%$ vs. $26.7 \%$; $\mathrm{p}<0.001)$.

Day workers and shift workers had similar serum levels of IL-6 ( $p=0.276)$, TNF- $\alpha(p=0.841)$ or lymphocytes count $(\mathrm{p}=0.404)$ (table 1$)$. Furthermore there were no differences in cytokine levels (IL-6 p $=0.761$;

Table 1 Influence of shift work and sleep quality by PSQI on IL-6, TNF- $\alpha$ and lymphocytes

\begin{tabular}{|c|c|c|c|c|}
\hline Component & Collective & Mean & $S D$ & $p$ \\
\hline IL-6 & $\begin{array}{l}\text { Daytime workers } \\
\text { Shift workers }\end{array}$ & $\begin{array}{l}2.30 \\
2.67\end{array}$ & $\begin{array}{l}1.54 \\
3.79\end{array}$ & 0.276 \\
\hline TNF- $\alpha$ & $\begin{array}{l}\text { Daytime workers } \\
\text { Shift workers }\end{array}$ & $\begin{array}{l}5.58 \\
5.68\end{array}$ & $\begin{array}{l}2.91 \\
5.19\end{array}$ & 0.841 \\
\hline Lymphocytes & $\begin{array}{l}\text { Daytime workers } \\
\text { Shift workers }\end{array}$ & $\begin{array}{l}33.68 \\
32.99\end{array}$ & $\begin{array}{l}7.64 \\
7.49\end{array}$ & 0.404 \\
\hline Component & PSQI & Mean & $S D$ & $p$ \\
\hline $\mathrm{IL}-6$ & $\begin{array}{l}\mathrm{PSQ} \mid \leq 6 \\
\mathrm{PSQ} \mid \geq 6\end{array}$ & $\begin{array}{l}2.47 \\
2.58\end{array}$ & $\begin{array}{l}2.50 \\
3.77\end{array}$ & 0.761 \\
\hline $\mathrm{TNF}-\alpha$ & $\begin{array}{l}\mathrm{PSQ} \mid \leq 6 \\
\mathrm{PSQ} \mid \geq 6\end{array}$ & $\begin{array}{l}5.53 \\
5.68\end{array}$ & $\begin{array}{l}3.49 \\
5.41\end{array}$ & 0.759 \\
\hline Lymphocytes & $\begin{array}{l}\mathrm{PSQ} 1 \leq 6 \\
\mathrm{PSQI} \geq 6\end{array}$ & $\begin{array}{l}33.59 \\
33.14\end{array}$ & $\begin{array}{l}7.52 \\
7.78\end{array}$ & 0.593 \\
\hline
\end{tabular}


TNF- $\alpha \mathrm{p}=0.759)$ or lymphocyte count $(\mathrm{p}=0.593)$ within the cohorts comparing their sleep quality (table $1)$. Neither when this calculations of sleep quality was stratified by shift and day workers, i.e. example, IL-6 concentration in day workers with good sleep quality was $2.31 \mu \mathrm{g} / \mathrm{ml}$ in comparison to $2.67 \mu \mathrm{g} / \mathrm{ml} \mathrm{IL-6} \mathrm{in}$ shift workers with good sleep quality (table 2). Comparing IL-6 concentration in respect to sleep quality shift workers with good sleep quality had a similar IL-6 levels $(2.67 \mu \mathrm{g} / \mathrm{ml})$ as their shift working colleges with relevant sleep disturbances $(2.72 \mu \mathrm{g} / \mathrm{ml})$ (table 2).

Multiple linear regression analysis showed a significant correlation of lymphocytes count and smoking habits. In contrast lymphocyte count and BMI, age, sleep quality or shift working status did not correlate. And there was no correlation of IL- 6 or TNF- $\alpha$ with any of the above mentioned parameters (table 3 ).

In a last step cytokine levels were correlated with blood cell counts. Linear regression analysis revealed no significant correlation of the cytokines and monocytes count (IL-6: $\beta=0.008 ; \mathrm{T}=0.153 ; \mathrm{p}=0.879$ or TNF- $\alpha$ : $ß=-0.025 ; \mathrm{T}=-0.475 ; \mathrm{p}=0.635)$ and neutrophils count (IL-6: $\beta=0.034 ; \mathrm{T}=-0.542 ; \mathrm{p}=0,588$; TNF- $\alpha$ : $B=-0.021 ; T=-0.343 ; p=0.732)$ as well as lymphocytes count (IL-6: $\beta=-0.002 ; \mathrm{T}=-0.036 ; \mathrm{p}=0.971$; TNF- $\alpha$ : $\beta=0.014 ; \mathrm{T}=0.256 ; \mathrm{p}=0.798$ ).

\section{Discussion}

The PSQI was used to evaluate sleep quality of the participants. Shift workers reported significantly worsened sleep quality compared to day workers. This is in line with many other authors who have demonstrated that shift work induces sleep disturbances and chronic sleep debt [1-6].

To investigate the long-term influence of chronic sleep debt and circadian disruption on the immune system we compared cytokine production and lymphocytes count in a morning blood sample of shift workers with

Table 2 Influence of sleep quality by PSQI on IL-6, TNF- $\alpha$ and lymphocytes stratified by shift and daytime worker

\begin{tabular}{|c|c|c|c|c|c|}
\hline Sleep quality & Component & Collective & Mean & $S D$ & $p$ \\
\hline \multirow[t]{3}{*}{$\mathrm{PSQ} \mid<6$} & IL-6 & $\begin{array}{l}\text { Daytime workers } \\
\text { Shift workers }\end{array}$ & $\begin{array}{l}2.31 \\
2.67\end{array}$ & $\begin{array}{l}1.59 \\
3.31\end{array}$ & 0.357 \\
\hline & TNF- $\alpha$ & $\begin{array}{l}\text { Daytime workers } \\
\text { Shift workers }\end{array}$ & $\begin{array}{l}5.51 \\
5.55\end{array}$ & $\begin{array}{l}3.01 \\
4.02\end{array}$ & 0.945 \\
\hline & Lymphocytes & $\begin{array}{l}\text { Daytime workers } \\
\text { Shift workers }\end{array}$ & $\begin{array}{l}33.98 \\
33.12 \\
\end{array}$ & $\begin{array}{l}7.60 \\
7.44 \\
\end{array}$ & 0.453 \\
\hline \multirow[t]{3}{*}{$\mathrm{PSQ} I \geq 6$} & IL-6 & $\begin{array}{l}\text { Daytime workers } \\
\text { Shift workers }\end{array}$ & $\begin{array}{l}2.06 \\
2.72\end{array}$ & $\begin{array}{l}0.31 \\
4.24\end{array}$ & 0.362 \\
\hline & TNF- $\alpha$ & $\begin{array}{l}\text { Daytime workers } \\
\text { Shift workers }\end{array}$ & $\begin{array}{l}5.54 \\
5.73\end{array}$ & $\begin{array}{l}2.06 \\
6.07\end{array}$ & 0.853 \\
\hline & Lymphocytes & $\begin{array}{l}\text { Daytime workers } \\
\text { Shift workers }\end{array}$ & $\begin{array}{l}32.85 \\
33.17\end{array}$ & $\begin{array}{l}8.26 \\
7.73\end{array}$ & 0.834 \\
\hline
\end{tabular}

Table 3 Standardized correlation coefficient (ß) with IL-6, TNF- $\alpha$ and lymphocytes in multiple regression analysis

\begin{tabular}{lllll}
\hline Component & Factor & $\boldsymbol{B}$ & $\boldsymbol{t}$ & $\boldsymbol{p}$ \\
\hline IL-6 & BMI & 0.103 & 1.842 & 0.066 \\
& Shift work & 0.049 & 0.820 & 0.413 \\
& Age & 0.006 & 0.103 & 0.918 \\
& Smoking & 0.100 & 1.794 & 0.074 \\
& sleep quality & 0.006 & 0.099 & 0.921 \\
\hline TNF- $\alpha$ & BMl & 0.025 & 0.447 & 0.656 \\
& Shift work & 0.010 & 0.168 & 0.866 \\
& Age & -0.016 & -0.275 & 0.783 \\
& Smoking & -0.022 & -0.400 & 0.690 \\
& sleep quality & 0.014 & 0.239 & 0.811 \\
\hline Lymphocytes & BMl & -0.043 & -0.771 & 0.441 \\
& Shift work & -0.005 & -0.088 & 0.930 \\
& Age & -0.068 & -1.208 & 0.228 \\
& Smoking & -0.170 & -3.092 & 0.002 \\
& sleep quality & -0.035 & -0.606 & 0.545 \\
\hline
\end{tabular}

daytime workers. Our results did not indicate an influence of shift work on cytokine levels of IL- 6 or TNF- $\alpha$ and lymphocyte cell count. Furthermore there was no association between sleep quality and these indicators of inflammation in this study.

Referring to cell counts Liu et al. reported a shortterm effect of a one night sleep deprivation on white blood cells and neutrophils, which we cannot find in our study setting looking for long-term effects [17].

Similarly, literature results on cytokine production are contradictive. E.g. Patel et al. described a direct association between the length of sleep and the increase of IL6 serum levels or the decline of TNF- $\alpha$ [7]. In contrast Prather et al. showed that self-reported higher sleep debt scores predict elevated cytokine-levels of IL-1ß and IL-6 [8]. As well Okun et al. found an association between bad sleep quality of pregnant women and elevation of IL-6 levels but no changes in TNF- $\alpha$ [29]. In their subsequent study in young healthy women IL-6 and TNF- $\alpha$ were not related with PSQI score and sleep duration, consistent with our data [30].

In another approach Vgontzas et al. reported shortterms effects of a one night-sleep deprivation, which changed the circadian pattern of IL-6 secretion [11]. And they observed similar effects in diseased people with chronic insomnia [12]. These results have to evoke the considerations that we might have missed possible differences as we have only investigated a single time point and no daytime secretion.

Our results support an association of IL-6 levels and smoking. Literature reveals smoking to be an important confounding factor for proinflammatory reaction and cardiovascular diseases [28,31]. Shift workers smoke more frequently independently from demographic 
factors as age, gender or education [26,32-34]. Even after adjusting shift workers and day workers in regards to the variables of age, socioeconomic status, physical activity, smoking, and occupational load the shift workers keep their elevated risk for cardiovascular diseases [35].

An association between shift work, BMI and cardiovascular risks can be suspected $[26,28,32]$. Therefore one would assume that higher BMI scores predict higher proinflammatory cytokines. Our data do not show any association between sleep disorders and BMI.

\section{Conclusion}

In summary, shift workers experience significantly more sleep disorders than day workers. Shift work induces chronic sleep debt. Our data reveals that chronic sleep debt might not always lead to an activation of the immune system, as we did not observe differences in lymphocyte count or level of IL- 6 or TNF- $\alpha$ serum concentration between shift workers and day workers. Therefore chronic sleep restriction might be eased by a long-term compensating immune regulation which (in healthy) protects against an overstimulation of proinflammatory immune mechanisms and moderates metabolic changes, as they are known from short-term sleep deprivation or sleep related breathing disorders. We can assume that long-term sleep debt in healthy may not lead to persistent proinflammatory changes in the immune system and to a consecutively higher risk for cardiovascular diseases. Further investigations are required to clarify the role of sleep in the immune system. Thus, most likely the increased cardiovascular disease risk of shift workers is caused from various parameters [28].

\begin{abstract}
Author details
'Institute of Occupational Medicine, University of Lübeck, 23538 Lübeck, Ratzeburger Allee 160, Germany. ${ }^{2}$ AUDI AG Ingolstadt, 85045 Ingolstadt, Germany. ${ }^{3}$ Department of Psychiatry and Psychotherapy, University of Lübeck, Ratzeburger Allee 160, 23538 Lübeck, Germany. ${ }^{4}$ Institute of Occupational Medicine, Charité - Universitätsmedizin Berlin, Free University and Humboldt-University, 14195 Berlin, Thielallee 73, Germany. ${ }^{5}$ European Research Society for Environment and Health in Transportation (EUGT) e. V., 14195 Berlin, Thielallee 73, Germany. ${ }^{6} \mathrm{C}$ linical Infectious Diseases, Research Center Borstel, 23845 Borstel, Germany.
\end{abstract}

\section{Authors' contributions}

AvM conceived of the study and its design, led the coordination, data collection, data analysis and interpretation of results and drafted the manuscript. SWW participated in the design of the study, data collection, data analysis and interpretation and in performing the statistical analysis. MSchroeder participated in the design of the study, study coordination, data collection, data analysis and interpretation and in performing the statistical analysis and took part in preparation of the manuscript. AO participated in the data collection, study coordination, data analysis and interpretation and in performing the statistical analysis and took part in preparation of the manuscript. KJC participated in the design of the study, data collection, data analysis and interpretation and took part in preparation of the manuscript. DAG participated in data interpretation and took part in preparation of the manuscript. MSpallek participated in the design of the study, study coordination and data collection. RK participated in the design of the study, study coordination, data interpretation and in preparation of the manuscript. BK participated in the design of the study, data analysis and interpretation and in drafting the manuscript. All authors read and approved the final manuscript.

\section{Competing interests}

The authors declare that they have no competing interests.

Received: 20 April 2010 Accepted: 5 July 2010 Published: 5 July 2010

\section{References}

1. Akerstedt T: Shift work and disturbed sleep/wakefulness. Occup Med (Lond) 2003, 53:89-94.

2. Costa G: Shift work and occupational medicine: an overview. Occup Med (Lond) 2003, 53:83-88.

3. Drake CL, Roehrs T, Richardson G, Walsh JK, Roth T: Shift work sleep disorder: prevalence and consequences beyond that of symptomatic day workers. Sleep 2004, 27:1453-1462.

4. Knutsson A: Methodological aspects of shift-work research. Chronobiol Int 2004, 21:1037-1047.

5. Sallinen M, Kecklund G: Shift work, sleep and sleepiness - differences between shift schedules and systems. Scand J Work Environ Health 2010, 36:121-133.

6. Sherman BW, Strohl KP: Management of shift work sleep disorder: Alice in Wonderland redux? J Occup Environ Med 46:1010-1012.

7. Patel SR, Zhu X, Storfer-Isser A, Mehra R, Jenny NS, Tracy R, Redline S: Sleep duration and biomarkers of inflammation. Sleep 2009, 32:200-204.

8. Prather AA, Marsland AL, Hall M, Neumann SA, Muldoon MF, Manuck SB: Normative Variation in Self-reported Sleep Quality and Sleep Debt is Associated with Stimulated Pro-inflammatory Cytokine Production. Biol Psychol 2009, 82:12-17.

9. Shearer WT, Reuben JM, Mullington JM, Price NJ, Lee BN, Smith EO, Szuba MP, van Dongen HP, Dinges DF: Soluble TNF-alpha receptor 1 and IL-6 plasma levels in humans subjected to the sleep deprivation model of spaceflight. J Allergy Clin Immunol 2001, 107:165-170.

10. Mullington JM, Hinze-Selch D, Pollmächer T: Mediators of inflammation and their interaction with sleep: relevance for chronic fatigue syndrome and related conditions. Ann N Y Acad Sci 2001, 933:201-210.

11. Vgontzas AN, Papanicolaou DA, Bixler EO, Lotsikas A, Zachman K, Kales A, Prolo P, Wong ML, Licinio J, Gold PW, Hermida RC, Mastorakos G, Chrousos GP: Circadian interleukin-6 secretion and quantity and depth of sleep. J Clin Endocrinol Metab 1999, 84:2603-2607.

12. Vgontzas AN, Zoumakis M, Papanicolaou DA, Bixler EO, Prolo P, Lin HM, Vela-Bueno A, Kales A, Chrousos GP: Chronic insomnia is associated with a shift of interleukin- 6 and tumor necrosis factor secretion from nighttime to daytime. Metabolism 2002, 51:887-892.

13. Ryan S, McNicholas WT: Inflammatory cardiovascular risk markers in obstructive sleep apnoea syndrome. Cardiovasc Hematol Agents Med Chem 2009, 7:76-81.

14. Ryan S, Taylor CT, McNicholas WT: Systemic inflammation: a key factor in the pathogenesis of cardiovascular complications in obstructive sleep apnoea syndrome? Postgrad Med J 2009, 85:693-698.

15. Yokoe T, Minoguchi K, Matsuo H, Oda N, Minoguchi H, Yoshino G, Hirano T, Adachi M: Elevated levels of C-reactive protein and interleukin-6 in patients with obstructive sleep apnoea syndrome are decreased by nasal continuous positive airway pressure. Circulation 2003, 107:1129-1134.

16. Yue HJ, Mills PJ, Ancoli-Israel S, Loredo JS, Ziegler MG, Dimsdale JE: The roles of TNF-alpha and the soluble TNF receptor I on sleep architecture in OSA. Sleep Breath 2009, 13:263-269.

17. Liu H, Wang G, Luan G, Liu Q: Effects of sleep and sleep deprivation on blood cell count and hemostasis parameters in healthy humans. $J$ Thromb Thrombolysis 2009, 28:46-49.

18. Mallon L, Broman JE, Hetta J: Sleep complaints predict coronary artery disease mortality in males: a 12-year follow-up study of a middle-aged Swedish population. J Intern Med 2002, 251:207-216.

19. Pickup JC: Inflammation and activated innate immunity in the pathogenesis of type 2 diabetes. Diabetes Care 2004, 27:813-823.

20. Resnick HE, Redline S, Shahar E, Gilpin A, Newman A, Walter R, Ewy GA, Howard BV, Punjabi NM, Sleep Heart Health Study: Diabetes and sleep 
disturbances: findings from the Sleep Heart Health Study. Diabetes Care 2003, 26:702-709.

21. Ridker PM, Hennekens $\mathrm{CH}$, Buring JE, Rifai N: C-reactive protein and other markers of inflammation in the prediction of cardiovascular disease in women. N Engl J Med 2000, 342:836-843.

22. Sesso HD, Wang L, Buring JE, Ridker PM, Gaziano JM: Comparison of interleukin-6 and C-reactive protein for the risk of developing hypertension in women. Hypertension 2007, 49:304-310.

23. Spiegel K, Leproult R, Van Cauter E: Impact of sleep debt on metabolic and endocrine function. Lancet 1999, 354:1435-1439.

24. Teramoto S, Yamamoto H, Ouchi Y: Increased C-reactive protein and increased plasma interleukin-6 may synergistically affect the progression of coronary atherosclerosis in obstructive sleep apnea syndrome. Circulation 2003, 107:E40-40.

25. van Leeuwen WM, Lehto M, Karisola P, Lindholm H, Luukkonen $R$, Sallinen $M$, Härmä M, Porkka-Heiskanen T, Alenius H: Sleep restriction increases the risk of developing cardiovascular diseases by augmenting proinflammatory responses through IL-17 and CRP. PLoS One 2009, 4: e4589.

26. Bøggild $\mathrm{H}$, Knutsson $\mathrm{A}$ : Shift work, risk factors and cardiovascular disease. Scand J Work Environ Health 1999, 25:85-99.

27. Ellingsen T, Bener A, Gehani AA: Study of shift work and risk of coronary events. J R Soc Promot Health 2007, 127:265-267.

28. Puttonen $S$, Härmä M, Hublin C: Shift work and cardiovascular disease pathways from circadian stress to morbidity. Scand I Work Environ Health 2010, 36:96-108.

29. Okun ML, Hall M, Coussons-Read ME: Sleep disturbances increase interleukin-6 production during pregnancy: implications for pregnancy complications. Reprod Sci 2007, 14:560-567.

30. Okun ML, Coussons-Read M, Hall M: Disturbed sleep is associated with increased C-reactive protein in young women. Brain Behav Immun 2009, 23:351-354.

31. Levitzky YS, Guo CY, Rong J, Larson MG, Walter RE, Keaney JF Jr, Sutherland PA, Vasan A, Lipinska I, Evans JC, Benjamin EJ: Relation of smoking status to a panel of inflammatory markers: the framingham offspring. Atherosclerosis 2008, 201:217-224.

32. Biggi N, Consonni D, Galluzzo V, Sogliani M, Costa G: Metabolic syndrome in permanent night workers. Chronobiol Int 2008, 25:443-454.

33. Puttonen $S$, Kivimäki M, Elovainio M, Pulkki-Råback L, Hintsanen $M$, Vahtera J, Telama R, Juonala M, Viikari JS, Raitakari OT, KeltikangasJärvinen L: Shift work in young adults and carotid artery intima-media thickness: The Cardiovascular Risk in Young Finns study. Atherosclerosis 2009, 205:608-613

34. van Amelsvoort LG, Schouten EG, Maan AC, Swenne CA, Kok FJ: Changes in frequency of premature complexes and heart rate variability related to shift work. Occup Environ Med 2001, 58:678-681.

35. Karlsson B, Knutsson A, Lindahl B, Alfredsson L: Metabolic disturbances in male workers with rotating three-shift work. Results of the WOLF study. International archives of occupational and environmental health 2003, 76:424-430.

doi:10.1186/1745-6673-5-18

Cite this article as: van Mark et al:: The impact of shift work induced chronic circadian disruption on IL- 6 and TNF- $\alpha$ immune responses. Journal of Occupational Medicine and Toxicology 2010 5:18.

\section{Submit your next manuscript to BioMed Central and take full advantage of:}

- Convenient online submission

- Thorough peer review

- No space constraints or color figure charges

- Immediate publication on acceptance

- Inclusion in PubMed, CAS, Scopus and Google Scholar

- Research which is freely available for redistribution

Submit your manuscript at www.biomedcentral.com/submit
Biomed Central 